\title{
DEVELOPMENT OF CRITICAL AND CREATIVE THINKING OF STUDENTS UNDER THE CONDITION OF THE CURRICULUM INTEGRATION IN SCHOOLS
}

\author{
GRETA JANI Ph.D \\ “Aleksandër Moisiu”, University \\ gretajani@yahoo.com
}

\begin{abstract}
:
The paper aims to analyze the impact of interdisciplinary integration on the development of critical thinking. Students today need to master the skills to solve difficult problems, critically examine circumstances, raise alternative opinions, and make prudent decisions to meet the challenges of today and the future. Teaching realized through interdisciplinary integration can make possible the demands that time places on students. To carry out the work, contemporary didactic literature related to interdisciplinary integration and the development of critical thinking was reviewed. The paper also contains a concrete field study. The population of this study were primary school students in Albania, parents and teachers. The champions of the study were two fourth graders in the school "Jakov Xoxa", Fier. The study was conducted while working on topics that rely on interdisciplinary integration. Observations conducted directly in the classroom, questionnaires with students, parents and teachers have provided significant results regarding the impact that interdisciplinary integration has on the development of critical and creative thinking during reading and writing. Interdisciplinary integration in all its dimensions helps and is part of the development of critical thinking by making students more motivated and realizing both the objectives of the school and the demands that time poses to students today.
\end{abstract}

Keywords: thematic learning, critical thinking, integration, interdisciplinary, etc.

\section{Introduction}

Children work in a class environment where they spend a great part of their time. When this environment is organized in a way that encourages the communication between the students, appreciates cooperation, integrates tasks and work materials and children are free to follow their ideas, they are eager to complete their tasks and to accept the challenges faced. Such models of teacher's roles and the environment conditions respect the children as the future thinkers (Brooks, 1993).

In the framework of a curriculum reform, it is important that the expected changes in particular components to include teaching and learning issues. Success in school requires an active learning process, renovated in content and shape, which is reflected on the use of methods, strategies and interactive contemporary teaching techniques. Interacting teaching exploits, the possibility of the contribute of each student found in the learning environment on their results, enables the possibility of knowledge being developed and not be taken for granted, makes the students collaborate with each other etc.

This study is focused on the area of education and more particularly in the pupil centered classes of the fourth grade in elementary education. The practice presented make the teachers change from a teacher centered method to student centered method. These methods give the pupil the chance for higher expression, freedom and recognition through manipulation and experience, while children develop critical and creative thinking. The school should assess the education as a process that aims to develop skills required in the today's world, away from the limitations that offer an incomplete curriculum. The acceptance of curriculum integration necessity is nothing but the beginning of a long 
reflecting process and decision making for methods of its integration in the national curriculum and the teaching practice in schools.

Education, as an important part of social life of the country, faced a lot of difficulties immediately after Albanian opening to the world. During political transition of 1990-1992, the education system inherited a great number of destructed school buildings. They were not appropriate for teaching process, without equipment and laboratories, lack of books and other learning materials (Group of authors, 2004). Moreover, changing of systems brought change in school curricula. In order to pass this inferiority and to realize a new content of generation education, an intensive qualification and requalification of all teachers and pedagogues was needed. In the center of the new curriculum, which aims to form students with a high level of learning, should be the development of critical and creative thinking. Knowing the techniques and methods to develop this thinking through activities of reading and writing and more, will give a new perspective to teaching and learning of children in schools.

\section{Development of critical and creative thinking through thematic method}

Curriculum integration is better realized through the thematic method or working with topics. Topic based teaching in a way or another touches and activates in various degrees the so called "Multiple Intelligence" in pupils.

Educative modern theories accept that individuals percept the world through at least seven different ways and all with the same importance: language (understanding the thought, influence on others, creating the ideas on the world and society etc.); logic analysis (finding the relation cause-result, classification, concluding, generalization, developing hypotheses, etc.); spatial perception (localization, finding the rations of space, imagination, idea presentations etc.); musical thinking (discovering and understanding rhythms, intonations, "hearing" of machinery movement, etc.); body movement ( idea understanding, feeling, skills, inner and outer impressions, tactics etc., expressed by body movements and visual expressions); self-recognition (knowing thy self, motives, emotions and inner feelings of each individuals); understanding others ( knowing and understanding the stimulatory motives or others' goals, "reading" of signs and expressions of others etc. (project "DANIDA").

As every teaching and learning methods, topic-based teaching wants to reach its objectives through: a) instructions (knowledge, statements, etc.) and b) expression (beliefs, values, etc.) where the specific weight of each of them depends of the topics, directive skills, the environment where the teaching happens, the historic-social-economic background and the traditional teaching in actual conditions.

It is already known that learning is the human act of trying to know the living reality. The objective of learning is to understand the knowledge and possession in order to use them. Each individual learns differently from others. Some individuals learn faster, some slower, some are active and some are passive etc. (Garo, 2008, p. 28 - 35). Learning is not just a collection of new concepts, skills, ideals, beliefs and ratings. More than these, learning is an integration of this collection which twines the pupils' personality. Transferring and acquiring skills and knowledge is crucial to the education process of children. Transferring means using the learning result in a new situation. (Garo, 2008, p. 40)

Thus, when a pupil uses skills learned in Math during an hour of Physics, we say a transferring has happened. The most successful teaching hours are the ones that stimulate the student to think by themselves and to participate in critical thinking (Halpem, 1995). Critical thinking enables us to assess our thinking, and to become aware of its nature.

That is why the aim of this study is the impact of the interdisciplinary integration on the development of critical thinking. Critical thinking is an active, interacting and complicated process performed through speaking and writing. This process is realized under conditions and environment that stimulate and support it. Critical and creative thinking is not part of a particular curriculum, an area or a special discipline, but is a process found in all the subjects regardless of the grades or cycles.

\section{Challenges encountered}


Apart from assessing the positive aspects of interdisciplinary integration and working with themes on the development of critical and creative thinking, the focus of this study is to discover the challenges encountered from teachers and students, as this type of teaching is not very frequent in the Albanian teaching experience. Many teachers do not have the necessary knowledge in all the main subjects to be able to fulfill the teaching requirements of the integrated curriculum.

First, a good part of the teachers does not have the sufficient knowledge in one particular subject to lead the pupils toward the complete knowledge of its main concepts.

Secondly, this problem becomes harder and harder when the teachers need to combine subjects with each other. If the teachers are not competent on the knowledge and concepts within the subject, then the interdisciplinary integration seems like a very hard thing for them. Selection and skillful use of topic-based teaching from elementary education teachers enables to lower the irregular behavior and effective learning. In fact, schools are in great need for interactive teaching.

Some of the characteristics of the new education curriculum require for it to have the pupils in its center, to fulfill their needs, interests and the society today and tomorrow, to be normal, with integrating emphasis, to stimulate the creative and critical thinking, and other basic skills and to enable the pupils the basic learning expressions during all their life. This curriculum should enable for the pupils not only subject knowledge, but also social life skills, civic values, deep impact on of TIC as a separate subject and as learning means implemented in all the other subjects, to give equal chances all the students by respecting their individual features, to be an advanced curriculum not only in the central level but also in the school level. (Pedagogic Journal, 2011).

Integrated curriculum is gift for talented and experienced teachers as it offers a new view to teach, while it helps the pupils to control their learning.

To realize or to build teaching for learning and in collaboration, teachers and students should fulfill some conditions, one of them is the common learning through topic-based teaching with projects or integration.

The degree, depth and the form of integration are conditioned by the features of subjects, topics, skill, values etc., necessary to be integrated. This means that integration is a dynamic process that depends from the changing needs of knowledge and skills acquisition and the learning situation.

Learning should be considered as a property of the pupils themselves, which is theirs and they should build and develop it further more. The knowledge that pupils get in school cannot and should not remain on the knowledge level, but the pupils should turn them into expressions and beliefs.

Pupils should go through a real action plan, individually or in group. Learning of this kind requires children to take risks, to hold critical beliefs for problems and real issues for which they have to make important decisions. In this view, is crucial to integrate learning activities, interdisciplinary or through school subjects. To respond to class interaction, the learning hour should change its profile: from a passive hour to an active, interacting hour which also makes the teachers and pupils' profile to completely change.

\section{Working with topics and critical thinking}

Working with topics as one of the used concepts in this study means the thematic teaching, the realization of the learning program integration, combines various topic areas, by exploring an interesting idea with the content from different themes. Topic-based teaching positively affects the change of the class relations, and further, as it makes the children more understanding, more acceptable to others. Children are friendlier with each other, more appreciative for classmates and themselves.

This study aims to investigate the impact of topic-based teaching in our schools, and the impact of this type of teaching on the pupils. We should keep in mind that there a lot of external and internal factors which impact the study results. Some of these limitations are: unqualified teachers, improper environment, lack of teaching materials, pupils of some levels, parents that are not included, the number of participants is relatively low, 50 pupils and parents and 10 teachers do not give a full result.

Topic-based teaching gives more possibilities to keep in mind, to realize or to complete social relations and some 
functions that relate to them, cultural identity and possible functions related to it, physical environment and functions related to it, daily life activities etc.

"First key to wisdom is the continuous questioning. Doubt takes us to investigation and investigation takes us to the truth"- states Peter Aberlard.

Many teachers are trying to change their practices to support the development of critical thinking during reading and writing. They want their students not to be simply reproductive, but to question, investigate, create, choose, interpret and debate the data or the facts given in respective materials. Such a teaching method today is widely accepted as "the best practice".

"Learning in full and productive way means that someone thinks of what he learns, implements the knowledge in the real life, uses it as a base to further learn, and learns independently" (Gardner, 1993).

Students who learn in a critical way are usually enthusiastic to learn. They are skilled to challenge the issues and discover in them possibilities to learn even in the most difficult tasks. These pupils pay attention to the possibilities to use their critical thinking skills and usually use these possibilities eagerly, being these in the classroom or out of it, in life.

Critical and creative thinking happens when students start to reflect to what they read, start to ask questions, create connections between the new learnt knowledge, select information, analyze behaviors, actions and situations, argument and hold certain beliefs. Teaching based on principles and methodology of critical and creative thinking creates classes with the center the pupil, creates powerful sets of learning. The teacher develops with the pupils integrated writing, speaking and reading activities, creates states where children search, learn, analyze, reflect and present their full potential, show not only what they know, but also what they are capable of doing. If we teach students to think critically then this should be done ongoingly in teaching practice (Zelina, 1994).

Topic teaching emphasize the activities that require critical thinking. Thematic teaching awakens the interest and curiosity to be appreciated as "skillful and original thinkers". They are offered circumstances and numerous possibilities to present their knowledge. This type of teaching increases the motivation. This is the common thing between topic teaching and critical thinking.

Teachers and education directors think that motivation and internal appreciation are the first sparkles that develop motivation in children to read and learn. In order to realize a topic teaching and to develop critical thinking of the students we should keep in mind some very important objectives: to encourage the pupils to question; to let the pupils decide by themselves for various things; to let children make mistakes; to appraise them for their efforts; to ask questions that do not need answers with "yes" or "no"; to become model of the critical thinking in classroom.

\section{Specific details on the study}

A special place holds the evaluation of this problem in the terrain in our schools. For this reason, we have distributed the questionnaires to parents, teachers and pupils. The school and classes were selected, and the sample was randomly selected. The school was "Jakov Xoxa" in the city of Fier, in classes where topic-based teaching was implemented. The study included 50 pupils, age 9-10 years. The questionnaire for the pupils was oriented, mainly with the questions like if they liked this job, if they felt safe with what they learned etc. Some main questions were: Did this task allowed you be creative and use your fantasy? - What do you like more in this task that you performed? - Did you feel freer?

Apart from pupils, the study also included 50 parents of these pupils. Some of the main questions in the parents' questionnaire were: - Do you think that the development of this task had a positive effect on your child? -In what direction? - what do you think of the teaching organization method in our education system? - How did you like the starting of this task?

Besides the pupils and their children, the study included ten teachers of this school who implemented the task of topic teaching in their classes. The teachers' questionnaires had ten questions focused on the impact that their teaching had on the increase of the quality of knowledge acquisition. Some of the main questions were: -Did this 
task have an impact on the change of class relations? In what direction? -Would this method be valuable to be applied in all schools? Why? -Do the pupils reach the school standards in all the subjects?

The impact of topic teaching was performed through direct survey. We surveyed all together 25 teaching hours. The higher advantage of using the survey technique is that it generates direct data from the natural environment where a certain behavior is studied.

The topics selected for the "Topic-based teaching" were various and in general they were suggested by pupils, so they were different from one class to the other. In order to collect the necessary data, we investigated the notes collected from the terrain surveys, giving us a more detailed view of the work impact and its effect on the development of critical thinking, emphasizing the talent of pupils in various areas.

\section{Conclusion}

The study revealed that the integrated curriculum and cross curriculum methodology helps to ensure meaningful learning and through lifetime. Actual studies support the fact that human understanding is more powerful when relations are established. Interdisciplinary integration enables the pupils the possibility to synthetize, analyze and use skills in complex contexts. The basic principle of integration should be: knowledge, skills, expressions should be considered as processes that accompany steady development and not only as content of learning texts.

In this view, integration in the new curriculum must be understood and treated not only as a union or mechanic relation of various subjects, neither as a new subject, but as a new dimension that should permeate every type of problem, issue, chapter or text. Above all, integration is much more than the mathematical sum of all subjects or chapters all together, as it creates a new level of similarities, synthesis comparison, relations, knowledge, endless perspectives, choices and selections equally dependent and related to each other.

Furthermore, "integration" should be concepted not only as a mechanic joining of disciplines, but as a synthesis of changes, connections, interactions, which does not ignore or avoids the particularities and values of each discipline or chapter, but accepts them in a higher synthesis level, where each subject or knowledge is valued and emphasized in the aspect of interrelation and interdependence. The achievement of the pupils showed the positivity of topic teaching with their learning. The parents were also satisfied with these results. The graphics below show the answers of the pupils' questionnaires.

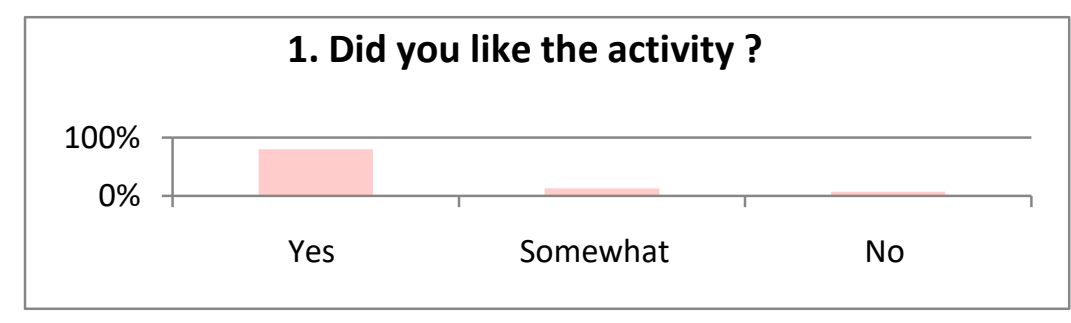

Figure 1. Pupils liked the topic teaching a lot, $80 \%$ of them expressed positively "yes". This for the fact that they like to be free and this I realized with the topic-based teaching. 


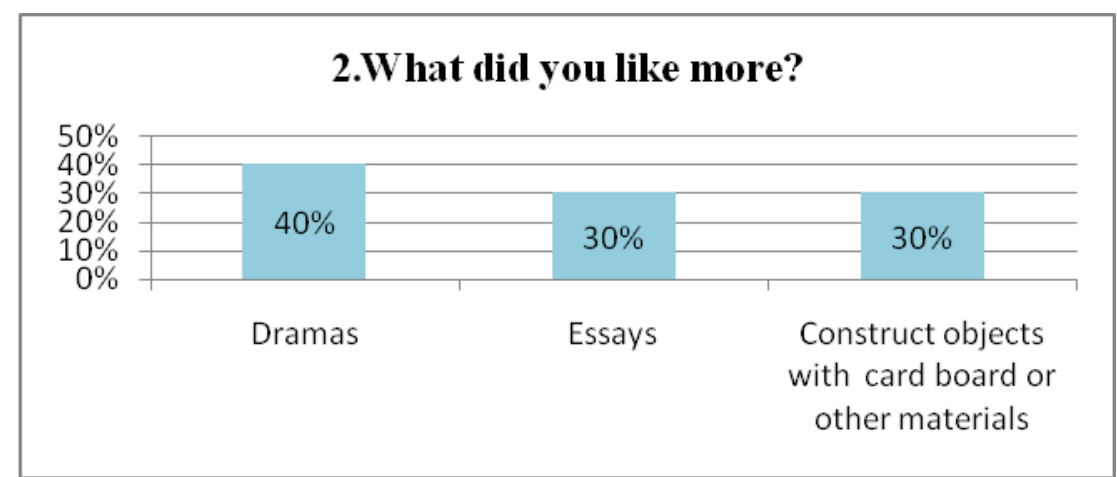

Figure 2. Pupils were divided in three groups, more pupils like dramas (40\%), as there they had more fun, and the number of pupils that liked the essays (30\%) was the same as the number of pupils that liked to build objects with different materials $(30 \%)$. Thus, this task made pupils more creative.

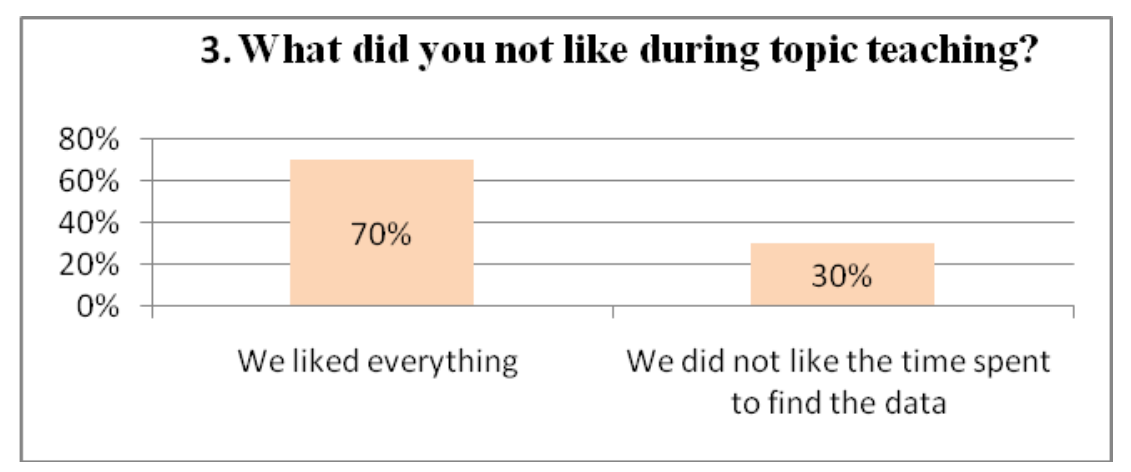

Figure 3. .Most of pupils stated that they were satisfied and liked the task (70\%). Topic teaching let them do things they liked more, but some of them did not like the time spent in finding the materials (30\%).

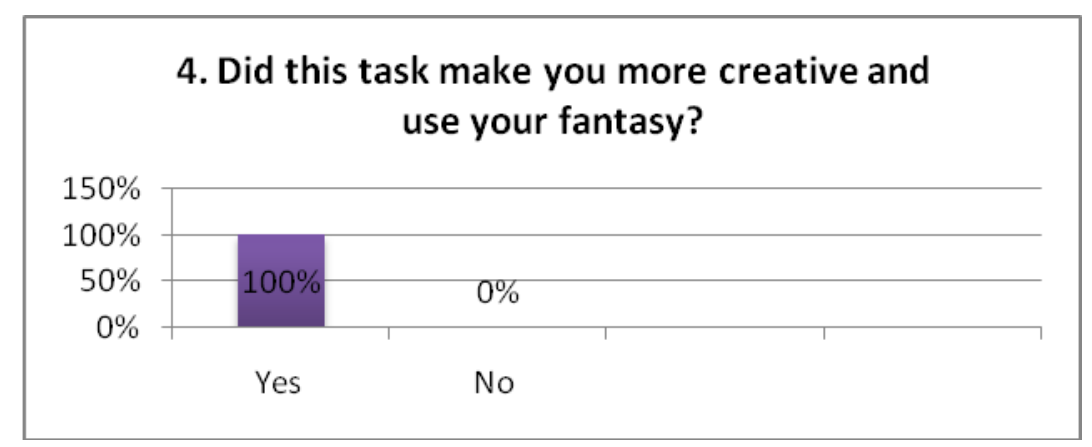

Figure 4. All pupils agreed that during these tasks they used their fantasy more, created more and learned more without getting tired, as the groups were divided according to their intelligence. 


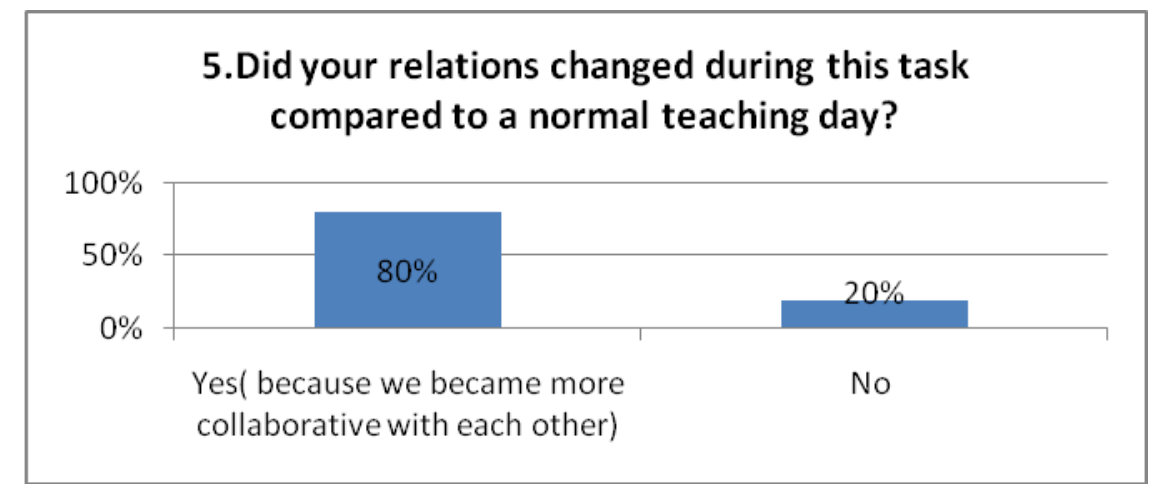

Figure 5. Most of the pupils state "yes" as they became more cooperative with each other, they even understood something new; the more cooperative they were with the classmates, the easier the problems. Collaboration is one of the main features of the topic-based teaching.

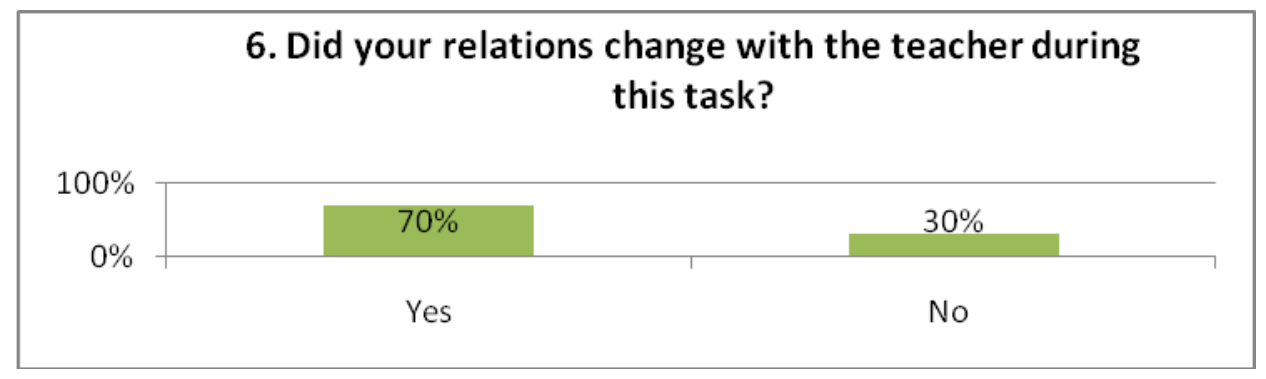

Figure 6. $70 \%$ accept that the relations changed, as the teacher was close to them, they were not afraid of failing to complete the task would make the teacher angry. So, the collaboration grew not only with each other but also with the teachers.

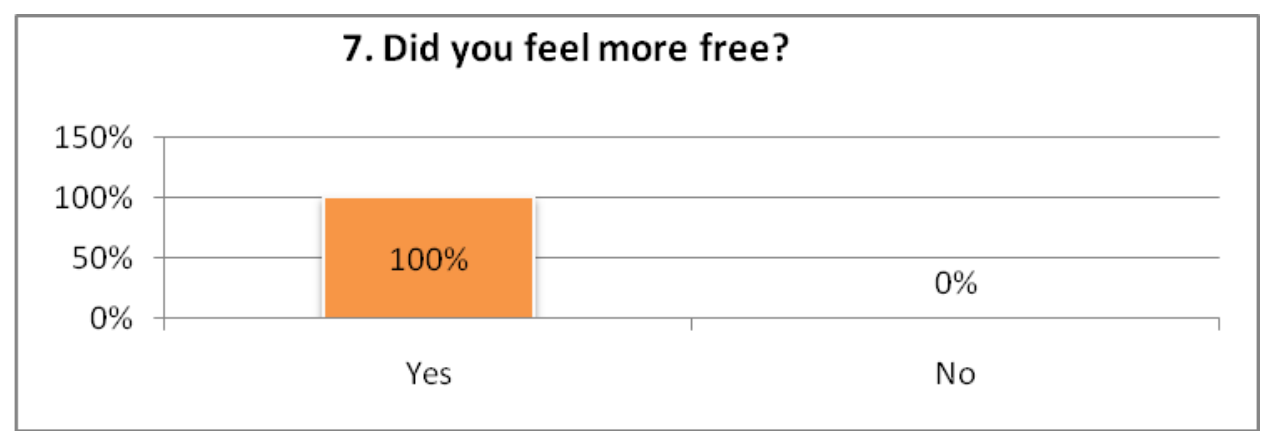

Figure 7. 100\% answered positively. They all felt free, a very important feature of interdisciplinary integration. The pupils did not work under pressure and were free resulting in better results for their tasks. 
ISSN 2661-2666 (Online) International Scientific Journal Monte (ISJM) DOI: $10.33807 /$ monte.20211833

Volume 4, (No).1 (2021): April

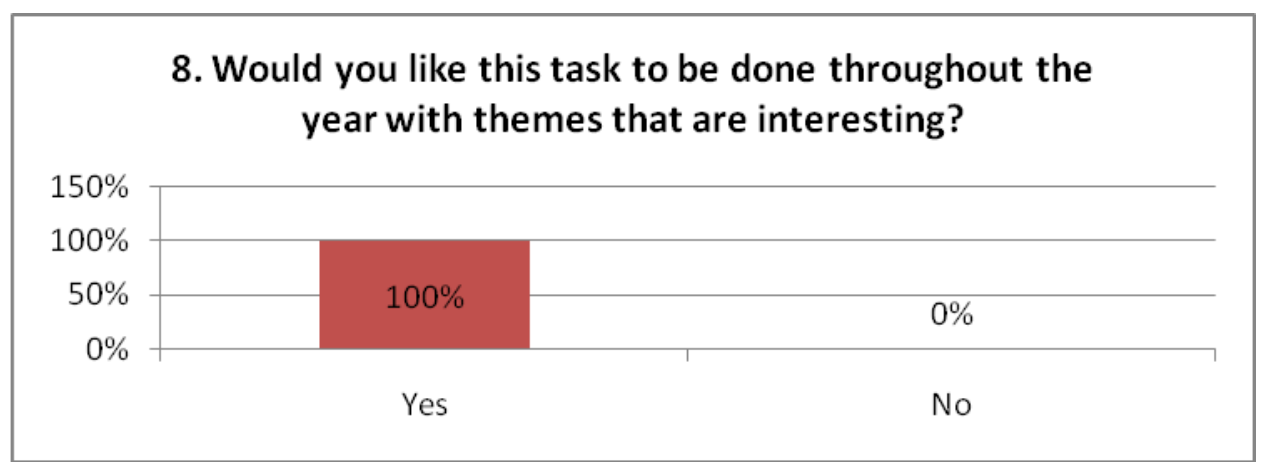

Figure 8. Everybody agreed that this teaching method should continue throughout the year, as they felt good, understood the topic, and liked the relation with the teacher as all the pupils worked and found themselves to be better in a certain area. 
ISSN 2661-2666 (Online) International Scientific Journal Monte (ISJM) DOI: 10.33807/monte.20211833

Volume 4, (No).1 (2021): April

\section{Bibliography}

Author group. (2004). School is ours, a vivid history from the start. Tirana, Albania: AEDP.

Brooks, M. and Grennon J. (1993). In search of understanding. The case of constructivist classrooms. Alexandria, VA: Association for supervision and Curriculum Development.

Gardner, H. (1993). Frames of mind: The theory of multiple intelligences. New York: Basic Books.

Garo, S. (2008). Contemporary teaching. Tirana, Albania: Toena.

Halpern, D (1995). Thought and knowledge: An introduction to critical thinking. Mahwah, NJ:Lawrence Earlbaum Associates;

Kurland, D. (1995). I know what it saws... What does it mean? Critical skills for critical reading. New York: Wadsworth.

Unrau, N. (1997). Thoughtful teachers, thoughtful learners: A guide to helping adolescents think critically. New York: Pippin.

www.izha.edu.al/materials/Revista_Pedagogjike_2011

Zelina, M. (1994). Strategie a metody rozvoja ososbnosti dietata. IRIS, Bratislava, Slovakia 